\title{
Correction to: Development of a highly sensitive fluorescence method for tartrazine determination in food matrices based on carbon dots
}

\author{
Lingfei Liu $^{1} \cdot$ Huijuan Sun ${ }^{1} \cdot$ Lixia Xiao ${ }^{1} \cdot$ Zhen-quan Yang $^{1} \cdot$ Jie $\mathrm{Han}^{2} \cdot$ Xiaojuan Gong ${ }^{3} \cdot$ Qin Hu $^{1,2}$
}

Received: 3 February 2021 / Accepted: 3 February 2021 / Published online: 12 February 2021

(C) Springer-Verlag GmbH Germany, part of Springer Nature 2021

\section{Correction to: Analytical and Bioanalytical Chemistry} https://doi.org/10.1007/s00216-020-03118-1

The authors would like to call the reader's attention to the fact that, unfortunately, there was an error regarding Fig. 1B in this manuscript; please find the correct figure below.

a

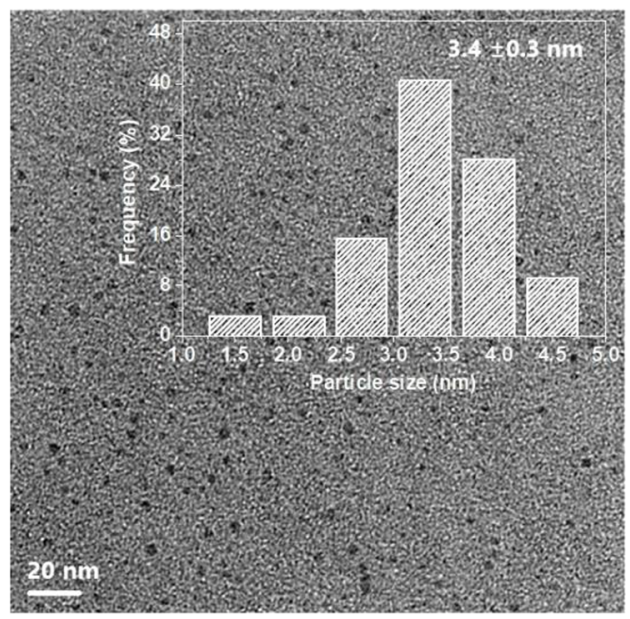

b

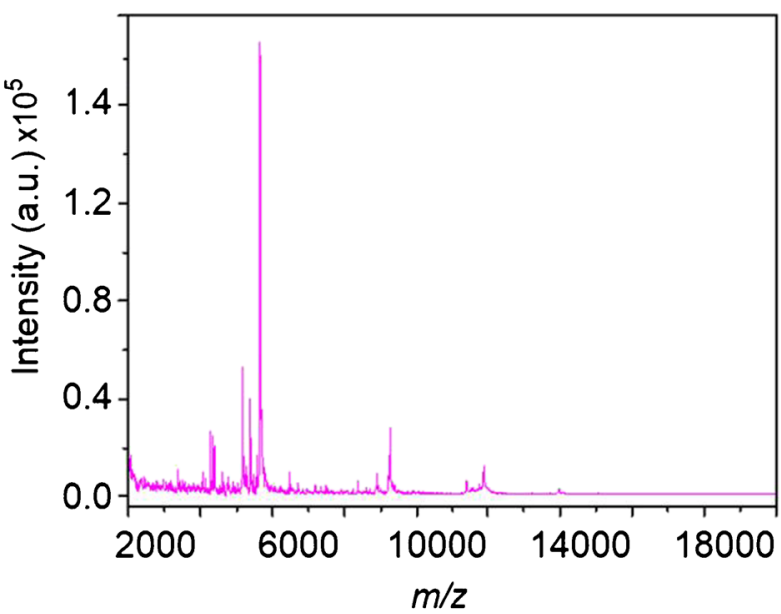

The original article has been corrected.

The online version of the original article can be found at https://doi.org/ 10.1007/s00216-020-03118-1

Publisher's note Springer Nature remains neutral with regard to jurisdictional claims in published maps and institutional affiliations.

Qin $\mathrm{Hu}$

qinhu@yzu.edu.cn

1 College of Food Science and Engineering, Yangzhou University, Yangzhou 225001, Jiangsu, China

2 School of Chemistry and Chemical Engineering, Yangzhou University, Yangzhou 225001, Jiangsu, China

3 Institute of Environmental Science, and School of Chemistry and Chemical Engineering, Shanxi University, Taiyuan 030006, China 